\title{
PREPARO DE HIDROLISADOS PROTÉICOS PARA A ANÁLISE DE AMINOÁCIDOS ${ }^{1}$
}

\author{
Carlos Roberto BERNARDI ${ }^{3, *}$, Marilde Terezinha Bordignon LUIZ ${ }^{3}$, \\ Dirceu Luiz ZANOTTO ${ }^{2}$, Antônio Lourenço GUIDONI²
}

\begin{abstract}
RESUMO
Amostras de milho, farelo de soja e hidrolisado ácido de caseína foram submetidas à hidrólise ácida em estufa $\left(110 \pm 5^{\circ} \mathrm{C}\right.$, durante 22 horas) com ácido clorídrico $6 \mathrm{~N}$, em ampolas de vidro seladas sob vácuo. Os hidrolisados foram preparados por quatro métodos: 1) evaporação em evaporador rotativo sob vácuo; 2) evaporação em câmaras a vácuo em presença de pastilhas de NaOH; 3) evaporação em bloco de aquecimento sob fluxo de argônio; 4) neutralização com solução padrão de citrato/NaOH. Os aminoácidos foram separados e quantificados em analisador específico Beckman System $6300 \mathrm{com}$ derivatização pós-coluna por ninidrina. O método de neutralização dos reagentes da hidrólise apresentou os melhores resultados considerando todos os aminoácidos. Além disso, foi mais rápido e prático no preparo de um grande número de amostras. Quanto aos métodos de evaporação, o uso de evaporador rotativo apresentou perdas significativas apenas para treonina e serina na amostra farelo de soja; sob fluxo de argônio observou-se baixos teores para treonina, fenilalanina e lisina; em câmara sob vácuo verificou-se perdas significativas para treonina, serina e tirosina.

Palavras-chave: aminoácidos; análise de aminoácidos; hidrólise de proteínas; preparo de amostras.
\end{abstract}

\section{SUMMARY}

PREPARATION OF PROTEIN HYDROLYSATES FOR AMINO ACID ANALYSIS. Samples of corn, soybean corn and casein (acid hydrolysate) were submitted to acid hydrolysis in oven $\left(110 \pm 5^{\circ} \mathrm{C}\right.$, for 22 hours) with $6 \mathrm{~N} \mathrm{HCl} \mathrm{in} \mathrm{sealed} \mathrm{ampoules} \mathrm{under} \mathrm{vacuum.} \mathrm{Four} \mathrm{methods} \mathrm{of}$ hydrolysate preparation were used: 1) evaporation to dryness in rotary evaporator under vacuum, 2) evacuated desiccator under vacuum and $\mathrm{NaOH}$, 3) flushing the open vial with argon and 4) neutralisation with standard citrate/NaOH solution. Amino acids were isolated and quantified in specific analyzer Beckman System 6300 with ninhidrin post-column derivatization. The neutralization method presented the best result considering all analysed amino acids. Besides, it was more practical for rapid processing of a large number of samples. With regard to the evaporation methods in the rotary evaporator, significant losses were verified only for threonine and serine in the soybean sample. Under flow of argon, low recoveries of threonine, phenylalanine and lysine where observed, whereas in the evacuated desiccator, significant losses of threonine, serine and tyrosine where verified.

Keywords: amino acid; amino acid analysis; protein hydrolysis; sample preparation.

\section{1 - INTRODUÇÃO}

$\mathrm{Na}$ análise de aminoácidos, avanços importantes foram obtidos quanto aos equipamentos e reagentes. Entretanto, muitos problemas ainda persistem, relacionados principalmente à hidrólise, ao preparo dos hidrolisados e à constituição da amostra. O método tradicional de hidrólise, com o uso de ácido clorídrico $6 \mathrm{~N}$ a $110^{\circ} \mathrm{C}$, é reconhecido como padrão e o mais utilizado, apesar de promover a destruição parcial ou total dos aminoácidos, especialmente cistina, metionina e triptofano.

Um parâmetro limitante que permanece no desenvolvimento da análise de aminoácidos é a confiança na preparação dos hidrolisados protéicos para o método cromatográfico, principalmente quanto à eliminação dos reagentes da hidrólise $[11,12,32]$. A neutralização ou evaporação dos agentes hidrolíticos é importante fator de discussão. O alto teor de sal resultante da neutralização, levado para a coluna de troca iônica, produz alargamento dos picos e não pode ser aplicado a todas as resinas, enquanto que a evaporação até a secagem pode acarretar perdas na recuperação dos aminoácidos durante esse procedimento $[4,15,30]$.

1. Recebido para publicação em 25/01/2000. Aceito para publicação em 13/05/2003 (000571).

${ }^{2}$ EMBRAPA Suinos e Aves, Caixa Postal 21, CEP 89.700-000, Concórdia-SC, Brasil.

${ }^{3}$ Departamento de Ciência e Tecnologia de Alimentos/CCA-UFSC, CEP 88. 034-001, Florianópolis-SC, Brasil.

* A quem a correspondência deve ser enviada.
O método mais comumente empregado para a eliminação dos reagentes da hidrólise é o da utilização de evaporadores rotativos sob vácuo $[5,7,14,17,20,22$, $24,30]$. Entretanto, para grandes quantidades de amostras torna-se um ponto crítico, pela morosidade e necessidade de acompanhamento contínuo, transformandose em condição de estrangulamento e demora na análise. Para diminuir o tempo na evaporação de amostras foram propostos procedimentos utilizando sistemas de evaporação para várias amostras simultâneas $[1,12,20$, 21].

Um tratamento alternativo, utilizado em muitos laboratórios, baseia-se na remoção dos reagentes em dessecadores ou câmaras a vácuo em presença de pastilhas de hidróxido de sódio e/ou pentóxido de fósforo [2, 13, 24].

O objetivo deste trabalho foi comparar metodologias de preparo dos hidrolisados protéicos por neutralização ou evaporação dos reagentes da hidrólise, para posterior análise de aminoácidos em amostras contendo baixo, médio e alto teor protéico.

\section{2 - MATERIAL E MÉTODOS}

Os experimentos envolvendo os testes de metodologias quanto ao preparo das amostras, hidrólise de proteínas, separação e quantificação dos aminoácidos foram realizados no Laboratório de Análises Fisico-Químicas da EMBRAPA Suínos e Aves, em Concórdia - SC. 


\section{1 - Material}

Foram utilizadas amostras de milho e farelo de soja, obtidas na fábrica de rações do CNPSA, e hidrolisado ácido de caseina bovina (Sigma A-2427).

\section{2 - Soluções e reagentes}

No preparo dos hidrolisados protéicos foram utilizados ácido clorídrico p. a. - $\mathrm{HCl}$ - (Reagentes Analíticos Dinâmica) e hidróxido de sódio p. a. - NaOH - (Vetec Química Fina). Para a evaporação dos hidrolisados em bloco digestor foi utilizado argônio 4.8, grau especial (White Martins). Para a neutralização dos agentes da hidrólise, foi preparada uma solução neutralizante $(10,5$ gramas de hidróxido de sódio p. a. dissolvido em $100 \mathrm{~mL}$ de solução tampão Na-S), como descrito por SPITZ [28].

Para a etapa de separação no analisador de aminoácidos Beckman System 6300, foram utilizadas as soluções tamponadas comerciais Na-A, Na-B, Na-D, Na-R, NaS e Nin-RX (Beckman), segundo SLOCUM et al. [26].

Foi preparada uma solução padrão contendo os aminoácidos: ácido aspártico (Asp), ácido glutâmico (Glu), treonina (Tre), prolina (Pro), glicina (Gli), alanina (Ala), valina (Val), leucina (Leu), tirosina (Tir), fenilalanina (Fen), lisina (Lis), arginina (Arg) (Merck), serina (Ser), norleucina (Nor) (INLAB), isoleucina (Ile) (SIGMA) e histidina (His) (ECIBRA), a 2,5 micromol por mililitro $(\mu \mathrm{mol} / \mathrm{mL})$ em $\mathrm{HCl}$ a $0,1 \%$. Para a solução padrão de norleucina $2,5 \mu \mathrm{mol} /$ $\mathrm{mL}$, foi pesada $32,80 \mathrm{mg}$ de norleucina e dissolvida em $100 \mathrm{~mL}$ HC1 0,1 N. Para a solução padrão de norleucina $1: 25,1 \mathrm{~mL}$ da solução padrão de norleucina $2,5 \mu \mathrm{mol} /$ $\mathrm{mL}$ foi evaporado e redissolvido em $25 \mathrm{~mL}$ da solução tampão de $\mathrm{Na}-\mathrm{S}$.

\section{3 - Métodos}

\subsection{1 - Preparo das amostras}

Todas as amostras foram finamente moídas em moinho Tecator Cyclotec (Foss - Tecator), utilizando peneira de $0,5 \mathrm{~mm}$. Foram determinados os teores de matéria seca (MS) pelo método de secagem em estufa a $105^{\circ} \mathrm{C}$ durante 24 horas [6], proteina bruta (PB) segundo o método 4.2.06 da AOAC [3], utilizando digestor 2020 e unidade de destilação 1026 da Foss - Tecator, extrato etéreo (EE) pelo método de Soxhlet utilizando unidade de extração Soxtec System 1040 da Foss - Tecator, cinzas (CZ) segundo o método 4.1.10 da AOAC [3] e aminoácidos, exceto metionina, cistina e triptofano para todas as amostras.

\subsection{2 - Hidrólise e preparo dos hidrolisados}

Para os métodos de evaporação dos reagentes da hidrólise, descrito nos sub-itens a, b e c, quantidades de milho, farelo de soja e caseina, contendo $4 \mathrm{mg}$ de proteína, foram hidrolisados com $1 \mathrm{~mL}$ de $\mathrm{HCl} 6 \mathrm{~N}$, durante 22 horas em estufa a $110 \pm 5^{\circ} \mathrm{C}$, em ampolas de vidro de $10 \mathrm{~mL}$. Para o método de neutralização dos reagentes da hidrólise, descrito no sub-item d, foram utilizadas quantidades das amostras de milho, farelo de soja e caseina, contendo aproximadamente 40mg de proteina, e hidrolisadas com $10 \mathrm{~mL}$ de $\mathrm{HCl} 6 \mathrm{~N}$ durante 22 horas em estufa a $110 \pm 5^{\circ} \mathrm{C}$, em ampolas de vidro de $10 \mathrm{~mL}$. O oxigênio foi retirado através de aspiração a vácuo e fluxo de nitrogênio (três vezes), e as ampolas com a amostra e ácido foram seladas sob vácuo e submetidas à hidrólise. A proporção de amostra (mg de proteína): $\mathrm{HCl}(\mathrm{mL})$ foi de aproximadamente $4: 1$ para todos os métodos [3], sendo que, para o método de neutralização foi utilizado uma quantidade dez vezes maior de ácido e amostra para evitar perdas de diluição. Os métodos de preparo dos hidrolisados protéicos foram desenvolvidos da seguinte forma:

a) Método 1 - Evaporador rotativo: O ácido utilizado na hidrólise foi evaporado em evaporador rotativo sob vácuo na temperatura de $50^{\circ} \mathrm{C}$. O tempo necessário para a completa evaporação foi de aproximadamente 25 minutos para cada amostra. O evaporado foi recuperado em $5 \mathrm{~mL}$ da solução de diluição Na-S Beckman e filtrado, primeiro em papel filtro de filtragem média e depois em membrana de celulose regenerada de $13 \mathrm{~mm}$ a 0,2 micron. O filtrado foi diluído $1: 1 \mathrm{com}$ a solução padrão de norleucina redissolvida 1:25.

b) Método 2 - Evaporação em dessecador a vácuo: O ácido foi evaporado em dessecador a vácuo em presença de $15 \mathrm{~g}$ de $\mathrm{NaOH}$ em pastilhas, até a completa evaporação dos reagentes da hidrólise [2, 13, 24]. O tempo necessário para a completa evaporação foi de aproximadamente 48 horas para cada lote de amostras. Cada lote foi composto por uma repetição de cada amostra. O evaporado foi recuperado e filtrado da mesma forma do Método 1, e diluído $1: 1$ com a solução padrão de norleucina redissolvida 1:25.

c) Método 3 - Evaporação em fluxo de argônio: $\mathrm{O}$ ácido foi evaporado com fluxo de argônio em bloco de aquecimento a $65^{\circ} \mathrm{C}$ até secar completamente $[12,20]$. O tempo necessário para a completa evaporação foi de aproximadamente 40 minutos para cada amostra. O evaporado foi recuperado e filtrado da mesma forma do Método 1, e diluído $1: 1$ com a solução padrão de norleucina redissolvida 1:25.

d) Método 4 - Neutralização: Os hidrolisados foram filtrados, primeiro em papel filtro de filtragem média, e depois em membrana de celulose regenerada de $13 \mathrm{~mm}$ a 0,2 micron, e neutralizados com a solução padrão de neutralização (na proporção de 1:2 de hidrolisado:solução padrão de neutralização). As amostras neutralizadas foram diluídas com solução tampão de diluição Na-S Beckman na proporção de 1:1 [28] e depois, diluídas novamente $1: 1$ com a solução padrão de norleucina redissolvida 1:25.

Foram realizadas cinco repetições para cada método e amostra, divididas em cinco blocos, onde os blocos foram compostos por uma repetição de cada método e amostra. Os blocos amostrais foram hidrolisados, preparados e submetidos à análise de forma independente e em datas diferentes.

Os aminoácidos foram quantificados em analisador específico Beckman System 6300 e os resultados comparados estatisticamente, conforme descrito no item 2.4. 


\section{4 - Análise estatística}

Os resultados encontrados em cada amostra foram submetidos previamente a uma análise de consistência, eliminando-se valores discrepantes (outliers), quando o coeficiente de variação entre as repetições para cada aminoácido foi maior que 10\% [16, 18, 25, 29].

Para a análise dos dados, foi adotado um modelo fatorial de $4 \times 3$, onde 4 foram os métodos e 3 foram as amostras, de acordo com STEEL \& TORRIE [29].

Este modelo foi aplicado, inicialmente, a um vetor de respostas envolvendo 15 aminoácidos: ácido aspártico, treonina, serina, ácido glutâmico, prolina, glicina, alanina, valina, isoleucina, leucina, tirosina, fenilalanina, histidina, lisina e arginina, para o qual foi realizada uma análise multivariada. Posteriormente, o mesmo modelo foi aplicado para cada aminoácido individualmente, através de análise univariada. Para a análise multivariada foram usados os dados originais e para a análise univariada os dados ajustados após a eliminação dos valores discrepantes.

As análises estatísticas foram processadas com o pacote estatístico SAS (Statistical Analysis System), versão 6.12 para Microsoft Windows 95 [23].

\section{3 - RESULTADOS E DISCUSSÃO}

São apresentados na Tabela 1 os teores de MS, PB, $\mathrm{EE}$ e CZ, das amostras de milho, farelo de soja e caseina (hidrolisado ácido), em g/100g da amostra íntegra. A composição para os 15 aminoácidos citados no item 2.4 nas amostras e métodos estudados, em valores médios são apresentados na Tabela 2.

O perfil de aminoácidos das amostras de milho, farelo de soja e caseína, nos dados não corrigidos, em g/100g de proteina na amostra integra é apresentado na Tabela 3.

Independentemente de amostra, para os 15 aminoácidos citados, analisados em conjunto através do vetor de médias, os métodos mostraram-se diferentes, apresentando interação entre métodos e amostras $(p<0,05)$. Devido à presença de interação entre métodos e amostras, todas as hipóteses foram testadas quanto ao seu comportamento para cada amostra, individualmente.

TABELA 1. Teores de matéria seca total (MS), proteína bruta (PB), extrato etéreo (EE) e matéria mineral (Cinzas) $^{(1)}$ nas amostras utilizadas nos experimentos, em g/ 100g da amostra integra.

\begin{tabular}{|c|c|c|c|c|}
\hline Amostra & $\begin{array}{c}\text { MS } \\
(\mathrm{g} / 100 \mathrm{~g}) \\
\end{array}$ & $\begin{array}{c}\mathbf{P B}^{(2)} \\
(\mathrm{g} / 100 \mathrm{~g})\end{array}$ & $\begin{array}{c}\mathbf{E E} \\
(\mathrm{g} / 100 \mathrm{~g}) \\
\end{array}$ & $\begin{array}{r}\text { Cinzas } \\
(\mathrm{g} / 100 \mathrm{~g}) \\
\end{array}$ \\
\hline Milho & 91,56 & 7,13 & 3,92 & 0,97 \\
\hline Farelo de Soja & 91,03 & 42,11 & 1,33 & 6,00 \\
\hline Caseína & 96,62 & 81,34 & 0,31 & 2,12 \\
\hline
\end{tabular}

Para a amostra milho não houve diferença entre os métodos. Com a amostra farelo de soja, os métodos de evaporação não diferiram entre si, enquanto que, em conjunto, foram diferentes do método de neutralização. Individualmente, o Método 3 (argônio) não apresentou diferença em relação ao método de neutralização. Para a amostra caseína, os métodos de evaporação mostraramse diferentes entre si, e também em relação ao método de neutralização, com exceção dos Métodos 3 e 4 . Os resultados médios obtidos em cada método nas amostras de milho, farelo de soja e caseina, respectivamente, são apresentados nas Tabelas 4 a 6.

Através da análise univariada verificou-se a presença de interação entre métodos e amostras $(p<0,05)$ para a treonina, serina, tirosina, fenilalanina e lisina, sendo que, para a treonina e a serina os métodos também resultaram diferentes nas amostras de farelo de soja e caseina, enquanto que, para a tirosina, fenilalanina e lisina os métodos resultaram diferentes apenas na amostra caseína. Para todos os demais aminoácidos não foram evidenciadas diferenças.

TABELA 2. Composição em aminoácidos das amostras de milho, farelo de soja e caseína, em g/ $100 \mathrm{~g}$ da amostra integra.

\begin{tabular}{lccc} 
Aminoácido & $\begin{array}{c}\text { Milho } \\
(\mathrm{g} / 100 \mathrm{~g})\end{array}$ & $\begin{array}{c}\text { Farelo de Soja } \\
(\mathrm{g} / 100 \mathrm{~g})\end{array}$ & $\begin{array}{c}\text { Caseína } \\
(\mathrm{g} / 100 \mathrm{~g})\end{array}$ \\
\hline Ácido aspártico & $0,45 \pm 0,01$ & $4,85 \pm 0,04$ & $3,47 \pm 0,06$ \\
Treonina & $0,24 \pm 0,00$ & $1,64 \pm 0,01$ & $2,36 \pm 0,04$ \\
Serina & $0,31 \pm 0,00$ & $2,07 \pm 0,02$ & $1,58 \pm 0,03$ \\
Ácido glutâmico & $1,23 \pm 0,01$ & $7,60 \pm 0,06$ & $16,07 \pm 0,26$ \\
Prolina & $0,49 \pm 0,01$ & $1,84 \pm 0,05$ & $9,32 \pm 0,21$ \\
Glicina & $0,26 \pm 0,00$ & $1,80 \pm 0,01$ & $1,70 \pm 0,03$ \\
Alanina & $0,48 \pm 0,01$ & $1,75 \pm 0,02$ & $5,15 \pm 0,08$ \\
Valina & $0,31 \pm 0,01$ & $1,87 \pm 0,04$ & $5,82 \pm 0,09$ \\
Isoleucina & $0,32 \pm 0,01$ & $2,72 \pm 0,06$ & $6,14 \pm 0,10$ \\
Leucina & $0,79 \pm 0,01$ & $3,13 \pm 0,03$ & $7,00 \pm 0,10$ \\
Tirosina & $0,18 \pm 0,00$ & $1,43 \pm 0,01$ & $2,69 \pm 0,05$ \\
Fenilalanina & $0,32 \pm 0,00$ & $2,14 \pm 0,02$ & $3,40 \pm 0,05$ \\
Histidina & $0,20 \pm 0,00$ & $1,06 \pm 0,01$ & $2,00 \pm 0,03$ \\
Lisina & $0,21 \pm 0,00$ & $2,52 \pm 0,02$ & $7,11 \pm 0,11$ \\
Arginina & $0,29 \pm 0,00$ & $2,99 \pm 0,03$ & $2,63 \pm 0,04$ \\
Total & $6,08 \pm 0,01$ & $39,41 \pm 0,03$ & $76,44 \pm 0,09$
\end{tabular}

Os teores, nos dados corrigidos, encontrado para os aminoácidos treonina, serina, tirosina, fenilalanina e lisina, nas amostras farelo de soja e caseina em g/100g da amostra íntegra, determinados por cada método, são apresentados nas Figuras 1 e 2.

Para essas variáveis, o método de neutralização dos reagentes da hidrólise (Método 4) mostrou-se mais eficiente, apresentando teores de aminoácidos mais elevados, com exceção da lisina e fenilalanina para a amostra caseina, onde foi mais eficiente o método de evaporação em evaporador rotativo (Método 1). Para a fenilalanina o Método 1 também apresentou maior teor, porém, estatisticamente não foi diferente do Método 4. O método de evaporação em câmaras a vácuo (Método 2) apresentou menores teores para os aminoácidos treonina, serina e tirosina, enquanto que o método de evaporação com aquecimento sob fluxo de argônio (Método 3) apresentou 
menores valores para fenilalanina e lisina. Na Figura 3 , essas diferenças podem ser visualizadas através dos valores relativos para a treonina, serina, tirosina, fenilalanina e lisina, calculados a partir da média de cada método pela média geral para a amostra caseína.

TABELA 3. Perfil de aminoácidos das amostras de milho, farelo de soja e caseína, nos dados não corrigidos, em g/100g de proteína da amostra integra.

\begin{tabular}{lccc}
\hline Aminoácido & $\begin{array}{c}\text { Milho } \\
(\mathrm{g} / 100 \mathrm{~g})\end{array}$ & $\begin{array}{c}\text { Farelo de Soja } \\
(\mathrm{g} / 100 \mathrm{~g})\end{array}$ & $\begin{array}{c}\text { Caseína } \\
(\mathrm{g} / 100 \mathrm{~g})\end{array}$ \\
\hline Ácido aspártico & 6,31 & 11,52 & 4,27 \\
Treonina & 3,37 & 3,89 & 2,90 \\
Serina & 4,35 & 4,92 & 1,94 \\
Ácido glutâmico & 17,25 & 18,05 & 19,76 \\
Prolina & 6,87 & 4,37 & 11,46 \\
Glicina & 3,65 & 4,27 & 2,09 \\
Alanina & 6,73 & 1,16 & 6,33 \\
Valina & 4,35 & 4,44 & 7,16 \\
Isoleucina & 4,49 & 6,46 & 7,55 \\
Leucina & 11,08 & 7,43 & 8,61 \\
Tirosina & 2,52 & 3,40 & 3,31 \\
Fenilalanina & 4,49 & 5,08 & 4,18 \\
Histidina & 2,81 & 2,52 & 2,46 \\
Lisina & 2,95 & 5,98 & 8,74 \\
Arginina & 4,07 & 7,10 & 3,23 \\
Total & 85,29 & 90,59 & 93,99
\end{tabular}

TABELA 4. Composição em aminoácidos na amostra milho, e comparação entre os métodos envolvendo as variáveis analisadas em conjunto, para os dados não corrigidos, em g/100g da amostra integra.

\begin{tabular}{lcccc}
\hline Aminoác ido & $\begin{array}{c}\text { Método 1 } \\
\text { (Evap. Rotativo) }\end{array}$ & $\begin{array}{c}\text { Mé todo 2 } \\
\text { (Dessec. Vácuo) }\end{array}$ & $\begin{array}{c}\text { Mé todo 3 } \\
\text { (Fluxo Argônio) }\end{array}$ & $\begin{array}{c}\text { Método 4 } \\
\text { (Neutralização) }\end{array}$ \\
\hline Ácido aspártico & $0,46 \pm 0,01$ & $0,46 \pm 0,01$ & $0,45 \pm 0,01$ & $0,43 \pm 0,02$ \\
Treonina & $0,25 \pm 0,00$ & $0,24 \pm 0,00$ & $0,24 \pm 0,01$ & $0,24 \pm 0,01$ \\
Serina & $0,31 \pm 0,00$ & $0,30 \pm 0,01$ & $0,32 \pm 0,01$ & $0,31 \pm 0,01$ \\
Ácido glutâmico & $1,23 \pm 0,02$ & $1,22 \pm 0,02$ & $1,24 \pm 0,02$ & $1,22 \pm 0,04$ \\
Prolina & $0,48 \pm 0,02$ & $0,51 \pm 0,03$ & $0,49 \pm 0,01$ & $0,50 \pm 0,03$ \\
Glicina & $0,27 \pm 0,01$ & $0,26 \pm 0,00$ & $0,26 \pm 0,00$ & $0,26 \pm 0,01$ \\
Alanina & $0,49 \pm 0,01$ & $0,48 \pm 0,01$ & $0,49 \pm 0,01$ & $0,47 \pm 0,01$ \\
Valina & $0,31 \pm 0,01$ & $0,31 \pm 0,01$ & $0,31 \pm 0,02$ & $0,30 \pm 0,01$ \\
Isoleucina & $0,33 \pm 0,01$ & $0,33 \pm 0,01$ & $0,32 \pm 0,02$ & $0,31 \pm 0,02$ \\
Leucina & $0,80 \pm 0,01$ & $0,80 \pm 0,01$ & $0,80 \pm 0,02$ & $0,78 \pm 0,02$ \\
Tirosina & $0,18 \pm 0,01$ & $0,18 \pm 0,01$ & $0,18 \pm 0,01$ & $0,17 \pm 0,01$ \\
Fenilalanina & $0,32 \pm 0,00$ & $0,32 \pm 0,00$ & $0,32 \pm 0,01$ & $0,31 \pm 0,01$ \\
Histidina & $0,20 \pm 0,01$ & $0,19 \pm 0,00$ & $0,20 \pm 0,00$ & $0,19 \pm 0,01$ \\
Lisina & $0,21 \pm 0,01$ & $0,20 \pm 0,00$ & $0,20 \pm 0,00$ & $0,22 \pm 0,01$ \\
Arginina & $0,30 \pm 0,01$ & $0,28 \pm 0,01$ & $0,29 \pm 0,01$ & $0,28 \pm 0,01$ \\
\hline Comparação do & \multirow{2}{*}{$\mathrm{a}$} & \multirow{2}{*}{$\mathrm{a}$} & $\mathrm{a}$ & $\mathrm{a}$ \\
vetor de médias ${ }^{(1)}$ & & & &
\end{tabular}

(1) - Vetor de médias ligado por letras distintas, diferem $(\mathrm{p}<0,05)$ quanto às variáveis conjuntas analisadas.

Baixas recuperações para treonina, serina, tirosina, fenilalanina e lisina também foram observadas por ou- tros autores, relacionadas principalmente à destruição por calor. Perdas para esses aminoácidos geralmente são associadas ao tempo e à temperatura da hidrólise, sendo a treonina e a serina as mais sensiveis [4, 12, 13, 17, 21].

No presente estudo, as condições de tempo e temperatura de hidrólise permaneceram constantes para todos os métodos e amostras analisadas, sugerindo outras possibilidades de perdas após a hidrólise ácida, que serão abordadas a seguir, quando os aminoácidos livres ainda podem sofrer reações [2].

Foram verificadas perdas significativas no Método 1 apenas para treonina e serina na amostra farelo de soja, perdas essas que podem ter ocorrido por aderência ao frasco quando da evaporação em evaporador rotativo $[4,13]$. Para evitar esse tipo de perdas, é citada a adição de pequena quantidade de glicerol ao frasco de hidrólise antes da evaporação [13].

TABELA 5. Composição em aminoácidos na amostra farelo de soja, e comparação entre os métodos envolvendo as variáveis analisadas em conjunto, para os dados não corrigidos, em g/100g da amostra íntegra.

\begin{tabular}{lcccc} 
Aminoácido & $\begin{array}{c}\text { Mé todo 1 } \\
\text { (Evap. Rotativo) }\end{array}$ & $\begin{array}{c}\text { Mé todo 2 } \\
\text { (Dessec. Vácuo) }\end{array}$ & $\begin{array}{c}\text { Método 3 } \\
\text { (Fluxo Argônio) }\end{array}$ & $\begin{array}{c}\text { Método 4 } \\
\text { (Neutralização) }\end{array}$ \\
\hline Ácido aspártico & $4,93 \pm 0,09$ & $4,86 \pm 0,08$ & $4,79 \pm 0,04$ & $4,81 \pm 0,12$ \\
Treonina & $1,62 \pm 0,04$ & $1,62 \pm 0,02$ & $1,64 \pm 0,02$ & $1,67 \pm 0,03$ \\
Serina & $2,03 \pm 0,04$ & $2,04 \pm 0,02$ & $2,11 \pm 0,02$ & $2,12 \pm 0,03$ \\
Ácido glutâmico & $7,71 \pm 0,15$ & $7,60 \pm 0,13$ & $7,54 \pm 0,05$ & $7,55 \pm 0,14$ \\
Prolina & $1,82 \pm 0,06$ & $1,92 \pm 0,07$ & $1,78 \pm 0,07$ & $1,85 \pm 0,15$ \\
Glicina & $1,82 \pm 0,05$ & $1,81 \pm 0,03$ & $1,79 \pm 0,01$ & $1,78 \pm 0,02$ \\
Alanina & $1,73 \pm 0,04$ & $1,77 \pm 0,03$ & $1,77 \pm 0,02$ & $1,73 \pm 0,05$ \\
Valina & $1,91 \pm 0,09$ & $1,93 \pm 0,08$ & $1,84 \pm 0,06$ & $1,81 \pm 0,10$ \\
Isoleucina & $2,80 \pm 0,12$ & $2,81 \pm 0,09$ & $2,66 \pm 0,09$ & $2,62 \pm 0,15$ \\
Leucina & $3,12 \pm 0,09$ & $3,16 \pm 0,04$ & $3,14 \pm 0,04$ & $3,10 \pm 0,07$ \\
Tirosina & $1,44 \pm 0,03$ & $1,46 \pm 0,02$ & $1,42 \pm 0,02$ & $1,42 \pm 0,01$ \\
Fenilalanina & $2,13 \pm 0,06$ & $2,15 \pm 0,02$ & $2,15 \pm 0,02$ & $2,12 \pm 0,05$ \\
Histidina & $1,06 \pm 0,02$ & $1,07 \pm 0,02$ & $1,06 \pm 0,02$ & $1,05 \pm 0,01$ \\
Lisina & $2,50 \pm 0,07$ & $2,52 \pm 0,06$ & $2,51 \pm 0,03$ & $2,53 \pm 0,05$ \\
Arginina & $3,02 \pm 0,09$ & $3,02 \pm 0,06$ & $2,97 \pm 0,03$ & $2,97 \pm 0,03$ \\
\hline Comparação do & \multicolumn{5}{c}{$\mathrm{a}$} & a & ab & $\mathrm{b}$ \\
vetor de médias ${ }^{(1)}$ & & & & \\
(1) - Vetor de médias ligado por letras distintas, diferem (p<0,05) quanto às variáveis \\
conjuntas analisadas.
\end{tabular}

No Método 2 as perdas verificadas para os aminoácidos treonina, serina e tirosina podem estar relacionadas à formação de compostos, como a transformação de ácido glutâmico e serina em $\mathrm{O}$ - $\gamma$-glutamilserina. Quando a evaporação é realizada em câmaras de vácuo, alguns autores sugerem que pode ocorrer a formação de o-sulfatos de serina e treonina com ácido cistéico, a formação de 3-clorotirosina ou 3-bromotirosina, e perdas por aderência ao frasco de hidrólise [2, 4, 5, 12, 13].

Os baixos teores observados para treonina, fenilalanina e lisina no Método 3 também podem estar relacionados à aderência ao frasco, como no Método 1 , agravado pelo fato do fluxo de argônio pressionar a so- 
lução contra a parede. Com exceção de treonina e serina para a amostra caseína, o Método 3 foi semelhante ao Método 4, também observado por CSAPÓ et al. [8], utilizando evaporação sob fluxo de nitrogênio.

TABELA 6. Composição em aminoácidos na amostra caseína, e comparação entre os métodos envolvendo as variáveis analisadas em conjunto, para os dados não corrigidos, em g/ $100 g$ da amostra íntegra.

\begin{tabular}{lcccc} 
Amin oácido & $\begin{array}{c}\text { Método 1 } \\
\text { (Evap. Rotativo) }\end{array}$ & $\begin{array}{c}\text { Método 2 } \\
\text { (Dessec. Vácuo) }\end{array}$ & $\begin{array}{c}\text { Método 3 } \\
\text { (Fluxo Argônio) }\end{array}$ & $\begin{array}{c}\text { Método 4 } \\
\text { (Neutralização) }\end{array}$ \\
\hline Ácido aspártico & $3,49 \pm 0,04$ & $3,25 \pm 0,19$ & $3,49 \pm 0,06$ & $3,63 \pm 0,04$ \\
Treonina & $2,42 \pm 0,03$ & $2,19 \pm 0,12$ & $2,37 \pm 0,05$ & $2,47 \pm 0,01$ \\
Serina & $1,59 \pm 0,02$ & $1,46 \pm 0,09$ & $1,62 \pm 0,04$ & $1,65 \pm 0,02$ \\
Ácido glutâmico & $16,25 \pm 0,17$ & $15,15 \pm 0,91$ & $16,31 \pm 0,31$ & $16,59 \pm 0,28$ \\
Prolina & $9,42 \pm 0,40$ & $8,69 \pm 0,55$ & $9,45 \pm 0,26$ & $9,71 \pm 0,39$ \\
Glicina & $1,75 \pm 0,02$ & $1,60 \pm 0,09$ & $1,71 \pm 0,03$ & $1,75 \pm 0,02$ \\
Alanina & $5,16 \pm 0,08$ & $4,94 \pm 0,26$ & $5,15 \pm 0,12$ & $5,33 \pm 0,07$ \\
Valina & $5,88 \pm 0,08$ & $5,57 \pm 0,23$ & $5,80 \pm 0,17$ & $6,02 \pm 0,17$ \\
Isoleucina & $6,17 \pm 0,09$ & $5,87 \pm 0,28$ & $6,16 \pm 0,20$ & $6,38 \pm 0,20$ \\
Leucina & $7,12 \pm 0,06$ & $6,73 \pm 0,36$ & $7,01 \pm 0,15$ & $7,15 \pm 0,09$ \\
Tirosina & $2,73 \pm 0,07$ & $2,51 \pm 0,16$ & $2,74 \pm 0,07$ & $2,79 \pm 0,02$ \\
Fenilalanina & $3,46 \pm 0,04$ & $3,26 \pm 0,19$ & $3,40 \pm 0,08$ & $3,46 \pm 0,03$ \\
Histidina & $2,06 \pm 0,02$ & $1,91 \pm 0,12$ & $2,01 \pm 0,05$ & $2,04 \pm 0,03$ \\
Lisina & $7,28 \pm 0,08$ & $6,80 \pm 0,39$ & $7,13 \pm 0,18$ & $7,20 \pm 0,15$ \\
Arginina & $2,65 \pm 0,03$ & $2,49 \pm 0,14$ & $2,67 \pm 0,08$ & $2,70 \pm 0,02$ \\
\hline Comparação do & $\mathrm{b}$ & $\mathrm{a}$ & $\mathrm{c}$ & $\mathrm{c}$ \\
vetor de médias ${ }^{(1)}$ & & & & \\
& & & &
\end{tabular}

(1) - Vetor de médias ligado por letras distintas, diferem $(p<0,05)$ quanto às variáveis conjuntas analisadas.

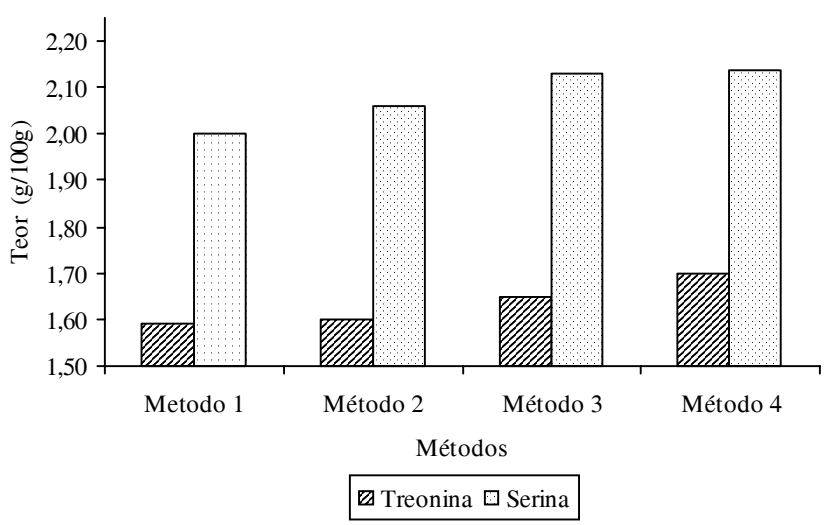

FIGURA 1. Teores de treonina e serina, determinados para cada método na amostra farelo de soja, em g/100g da amostra integra, nos dados corrigidos (Método 1: evaporador rotativo; Método 2: câmaras sob vácuo; Método 3: fluxo de argônio; Método 4: neutralização).

Para os demais aminoácidos, menores teores foram observados nos métodos de evaporação (1, 2 e 3), em comparação com o método de neutralização (4), também podem estar relacionados à aderência ao frasco de hidrólise, porém, essas diferenças não foram estatisticamente significativas.

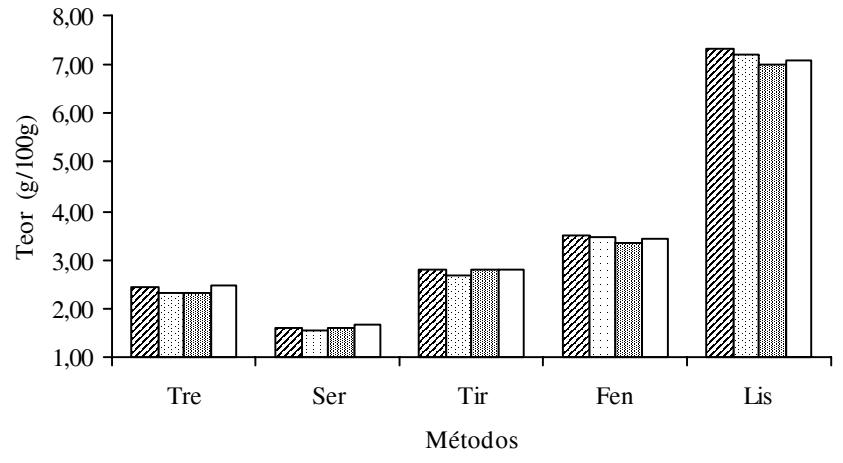

Método 1 Método 2 田 Método $3 \square$ Método 4

FIGURA 2. Teores de treonina, serina, tirosina, fenilalanina e lisina determinados para cada método na amostra hidrolisado ácido de caseína, em g/100g da amostra íntegra, nos dados corrigidos (Método 1: evaporador rotativo; Método 2: câmaras sob vácuo; Método 3: fluxo de argônio; Método 4: neutralização).

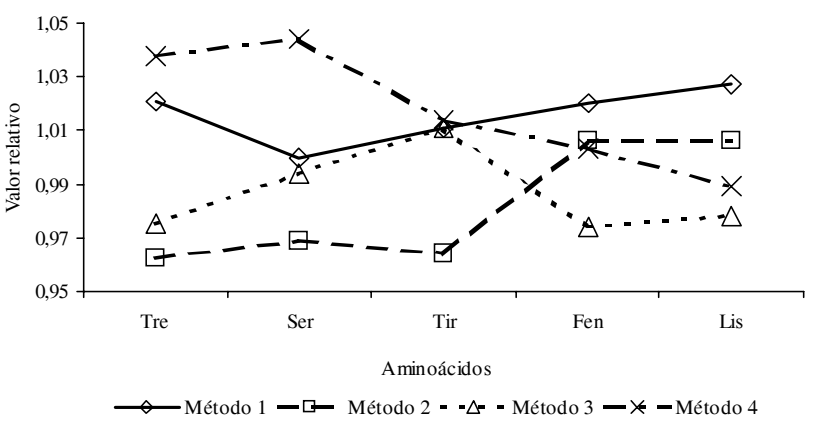

FIGURA 3. Comparação entre os métodos para a amostra caseína, através de valores relativos à média (Método 1: evaporador rotativo; Método 2: câmaras sob vácuo; Método 3: fluxo de argônio; Método 4: neutralização).

O Método 4 diferiu do Método 1 apenas para a treonina na amostra farelo de soja e lisina na amostra caseina. Entretanto, no conjunto, apresentou maiores teores para a maioria dos aminoácidos.

Nas condições deste experimento, o método de neutralização dos reagentes da hidrólise (Método 4), proposto por SPITZ [28], CSAPÓ et al. [8], BECH-ANDERSEN et al. [4], PECAVAR et al. [19] e CSAPÓ et al. [9], não ocasionou problemas de separação dos aminoácidos. Além disso, mostrou-se mais prático e rápido para o processamento de grandes quantidades de amostras, fato também verificado por CSAPÓ et al. [8].

\section{4 - CONCLUSÕES}

- A recuperação para os aminoácidos sensiveis a perdas variou em função do tipo de material analisado e do método utilizado.

- Para a maioria dos aminoácidos, a maior taxa de recuperação foi encontrada com o método de 
neutralização dos reagentes de hidrólise, que também mostrou-se mais rápido e prático, atendendo às necessidades de trabalho com um grande número de amostras.

- Os métodos de evaporação em evaporador rotativo e aquecimento sob fluxo de argônio necessitam de testes, considerando a proteção dos aminoácidos contra a aderência à parede do frasco de hidrólise.

- O método de evaporação em câmaras sob vácuo em presença de $\mathrm{NaOH}$ apresentou perdas significativas para treonina e serina na amostra farelo de soja, e treonina, serina e tirosina na amostra caseina.

- Não foram observadas diferenças entre os métodos para a amostra milho.

\section{5 -REFERÊNCIAS BIBLIOGRÁFICAS}

[1] ALEGRÍA TORAN, A.; BARBERÁ, R.; FARRÉ, R.; LAGARDA, M. J.;LÓPEZ, J. C. HPLC method for cyst(e)ine and methionine in infant formulas. J. of Food Science, v. 61, n. 6, p. 1132-1135 e 1170, 1996.

[2] AMBLER, R. P. Standards and accuracy in amino acid analysis. In: RATTENBURY, J. M. Amino Acid Analysis. Chichester: Ellis Horwood, 1981. 380p.

[3] AOAC INTERNATIONAL. Official Methods of Analysis of AOAC, 16 ed. Arlington (USA): 1995. Ch. 4, p 4-4H.

[4] BECH-ANDERSEN, S., MASON; V. C. DHANOA, M. S. Hydrolysate preparation for amino acid determinations in feed constituents. J. of Animal Phisiology and Animal Nutritions, v. 63, n. 4, p. 188-197. Apr, 1990.

[5] BENSON, J.; LOUIE, P. C.; BRADSHAW, R. A. Amino acid analysis of peptides. In: The Peptides, v. 4, Academic Press, 1981. Ch. 5, p $217-260$.

[6] BRASIL. Ministério da Agricultura. Departamento Nacional de Defesa Animal. Divisão de Laboratório Animal. Métodos Analíticos de Controle de Alimentos para Uso Animal. São Paulo: Anfar, 1992. 208p.

[7] CHEN, S. T.; CHIOU, S. H.; CHU, Y. H.; WANG, K. T. Rapid hydrolysis of proteins and peptides by means of microwave technology and its application to amino acid analysis. Int. J. Peptide Protein Res, v. 30, p. 572576, 1987.

[8] CSAPÓ, J.; TOTH-POSFAI, I.; CSAPO-KISS, Z. Optimization of hydrolysis in the determination of amino acid contents in food and feed products. Acta Aliment. v. 15, n. 1, p. 3-21, 1986.

[9] CSAPÓ, J.; CSAPÓ-KISS, Z.; FOLESTAD, S.; TIVESTEN, A. Mercaptoethanesulphonic acid as a protecting and hydrolysing agent for the determination of the amino acid composition of proteins using an elevated temperature for protein hydrolysis. Analytica Chimica Acta, v. 289, n. 1, p. 105-111, 1994.

[10] DINTZIS, F. R., CAVINS, J. F.; GRAF, E. \& STAHLY, T. Nitrogen-to-protein conversion factors in animal feed and fecal samples. J. Animal Sci, v. 66, p. 5-11, 1988.

[11] FOUNTOULAKIS, M.; LAHM, H. W. Hydrolysis and amino acid composition analysis of proteins. J. of Chromatography A, v. 826, p. 109-134, 1998.

[12] GEHRKE, C. W.; WALL, L. L.; ABSHEER, J. S.; KAISER, F. E; ZUMWALT, R. W. Sample preparation for chromatography of amino acids: acid hydrolysis of proteins. J. Assoc. Off. Anal. Chem, v. 68, n. 5, p. 811$821,1985$.
[13] LANFER MARQUEZ, U. M. Preparo de amostras para a análise de aminoácidos em proteínas alimentares. Bol. SBCTA. vol 30, n. 1, p. 19-27, 1996.

[14] LEBET, V.; SCHNEIDER, E. A.; AMADÓ, R. A critical appreciation of the protein determination by Kjeldahl's method based on the amino acid analysis. Mitt. Gebiete Lebensm. Hyg, v. 85, n. 1, p. 46-58, 1994.

[15] LLAMES, C. R.; FONTAINE, J. Determination of amino acids in feeds: collaborative study. J. of AOAC International, v. 77. No. 6, p. 1362-1402, 1994.

[16] CANTARELLA, H. \& QUAGGIO, J. A. Controle de qualidade dos resultados analíticos. In: Manual de análises químicas de solos, plantas e fertilizantes/Embrapa Solos, Embrapa Informática Agropecuária; Organizador Fábio Cesar da Silva. Brasília: Embrapa Comunicação para Transferência de Tecnologia, 1999.

[17] MARCONI, E.; PANFILI, G.; BRUSCHI, L.; VIVANTI, V.; PIZZOFERRATO, L. Comparative study on microwave and conventional methods for protein hydrolysis in food. Amino Acids, v. 8, n. 2, p. 201-208, 1995.

[18] MONTGOMERY, D. C. Design and Analysis of Experiments. 3 ed. New York: John Wiley \& Sons, 1991. 649 p.

[19] PECAVAR, A.; PROSEC, M.; FERCEJ-TEMELJOTOV, D.; MARSEL, J. Quantitative evaluation of amino acids using microwave accelerated hydrolysis. Chromatographia, v. 30, n. 3-4, p. 159-162, 1990.

[20] PÉTER, A.; LAUS, G.; TOURWÉ, D.; GERLO, E.; VAN BINST, G. An evaluation of microwave heating for the rapid hydrolysis of peptide samples for chiral amino acid analysis. Peptide Research, v. 6, n. 1, p. 48-52, 1993.

[21] PHILLIPS, D. D. A scheme for the rapid preparation of protein hydrolysates for amino acid analysis. J. of Food Science, v. 48, p. $284-285,1983$.

[22] ROACH, D.; GEHRKE, C. W. The hydrolysis of proteins. J. of Chromatography, v. 52, p. 393-404, 1970.

[23] SAS Institute Inc. System for Microsoft Windows, release 6.12, Cary, NC, USA, 1996.

[24] SAVOY, C. F., HEINIS, J. L.; SEALS, R. G. Improved methodology for rapid and reproducible acid hidrolysis of food and purified proteins. Analytical Biochemistry, v. 68, p. 562-571, 1975.

[25] SILVA, L. R. O. da. A análise da variância como ferramenta para a melhoria da qualidade metrológica em laboratórios. In: Enqualab - 2001: Encontro para a qualidade de laboratórios. São Paulo: Remesp, 2001.

[26] SLOCUM, R.; LEE, P. ; ARRIZON-LOPEZ, V. Standard protein hydrolysate analysis, alternate third buffer $(\mathrm{Na}-$ D). System 6300/7300 Application Notes. Beckman Instruments, Inc., Palo Alto, CA, 1987.

[27] SOSULSKI, F. W. \& IMAFIDON, G. I. Amino acid composition and nitrogen-to-protein conversion factors for animal and plant foods. J. Agric. Food Chem, v. 38, p. 1351-1356, 1990.

[28] SPITZ, H. D. Amino acid determination - hydrolysis procedure. Anal. Biochem, v. 56, p. 66-73, 1973.

[29] STEEL, R. G. D.; TORRIE, J. H. Principles and Procedures of Statistics - A Biomedical Approach. 2 ed. Auckland: McGraw-Hill International Book Company, 1981. 633 p.

[30] VAN DER MEER, J. M. Amino acid analysis in the Netherlands: Four-Year Proficiency Study. J. Assoc. Off. Anal. Chem, v. 73. No. 3, p. $394-398,1990$.

[31] YAMAGUCHI, M. Determination of the nitrogen-to-protein conversion factor in cereals. Moderne Methoden der Pflanzenalyse, v. 14(seed anal.), p. 95-107, 1992.

[32] ZUMWALT, R. W.; ABSHEER, J. S.; KAISER, F. E.; GEHRKE, C. W. Acid hydrolysis of proteins for chromatographic analysis of amino acids. J. Assoc. Off. Anal. Chem, v. 70, no. 1, p. 147-151, 1987. 